\title{
Strategies for the Service Industry to Effectively Overcome the Crisis: Meituan's Specific Practices During COVID-19
}

\author{
Yuhan Gong ${ }^{1}$, Haoying $\mathrm{Li}^{2 *}$, Jianfeng $\mathrm{Liu}^{3}$, Dang Weng ${ }^{4}$ \\ ${ }^{1}$ Maple Leaf International School-Shanghai, Shanghai 200231, China \\ ${ }^{2}$ Mountain View International Hefei No.1 High School, Hefei, Anhui 230601, China \\ ${ }^{3}$ YINGHUA INTERNATIONAL SCHOOL, Tianjin 301799, China \\ ${ }^{4}$ Suzhou Foreign Language School, Suzhou, Jiangsu 215011, China \\ *Corresponding author: Email: lihaoying0215@gmail.com
}

\begin{abstract}
Here we describe that all companies are experiencing a crisis during COVID-19. The four authors found that five strategies are feasible by investigating the measures of other companies. Using the analysis of research companies, four of these strategies can help the food delivery industry to tide over difficulties in the current period. The strategy of "innovation and transcendence" is a brand-new door-to-door service based on the peculiarities of pneumonia infection, which is more convenient than the original physical store purchase. The second strategy is called "infuse and augment", which makes up for losses by adding other industries. Meituan expands hotel services to reduce losses. The next step is "attraction and promotion", which is to attract more customers' desire for consumption through advertising settings on electronic products and strengthen brand awareness. Finally, "imitating and strengthening" will make the brand the best in this field. Meituan has made changes to the management system through analysis of competing companies to gain more satisfaction and brand loyalty.
\end{abstract}

Keywords: relationship between companies, financial crisis in COVIN-19, Meituan, balance the price and the quality, current market environment

\section{INTRODUCTION}

The outbreak of the coronavirus in 2020 had a farreaching impact all over the world. Life is no longer the same. Among those industries particularly devastated by the epidemic, hospitality sector such as traditional hotels and restaurants is on top of the list. Even though customers were confined at home, these establishments had to pay for labor, rent and a variety of other fix charges. According to a survey conducted by State Bureau of PRC, index of express service quality increased by $80.1 \%$ in February, 2020. According to a survey of the China Hotel Association, 1.23 billion yuan was lost in 7 days of the Spring Festival Holiday in 2020 [1]. However, there are sectors that exploded during the health crisis. Another survey conducted by CCFA claims that enterprises that provide service delivered to home generally increased over $80 \%$ [2]. The same survey also points out that online retail also grew tremendously during the same period. What's their secret?
In this article, we are going to review the innovative and creative marketing strategies adopted by tourism firms to navigate during the crisis. We are first going to use Secondary Research methods by reading materials published previously and sorting out some typical strategies that firms tend to use in economic recession. Finally, we will summarize and analyze how to manage the disorder brought by the epidemic.

\section{LITERATURE REVIEW}

Crises are not new, a lot of company go through a crisis in the past, often in times of economic crises. Therefore, we know from past researches there are certain things that companies can do when they are facing a crisis. We have identified five different strategies.

- The first strategy is called Make relationships count. The relationships and reputation that a company has cultivated over the years may save a company that is about to go bankrupt in difficult times. When people have 
limited resources, their choice is often to go with someone whose work they know and trust [3].

- Keep in touch with customers then increase customer loyalty is another strategy. It can not only maintain product sales but also strengthen word-ofmouth publicity and reduce sales promotion, advertising, and other marketing expenses [4].

- The next strategy is not to lower the price of the brand during the crisis. If the brand lowers the price, it will be difficult to return to the original price once the crisis is over. Because the product is already at a disadvantage when the price is reduced, customers attracted by the low price will be dissatisfied with the rising price or even stop buying [5].

- Integrating into the current market environment and following the trend is necessary. To increase the diversity of publicity and sales, you can choose remote service or door-todoor service to make consumers distinguish your company from rivals [6].

- The last strategy is to maintain the publicity of the company. The customer's memory of the brand is limited, and the cost of advertising is indispensable. The threshold of online publicity is very low, and the video platform can be used to increase the company's attention [7].

These five strategies have helped many companies survive through crisis in the past, but the development of covid-19 seems to have become more serious in today's globalized market.

And the damaged area has also turned into the tourism industry. Are the five strategies introduced still effective for the tourism industry? Should it continue to be used by travel companies? Is there any need for tourism companies to learn from history when dealing with crises in the future? We will find out those questions by researching.

Combining the strategy with the actual situation, we have some information from official sources to support the effectiveness of the strategy.

\section{ANALYSIS}

Meituan formerly Meituan-Dianping, is a Chinese shopping platform for locally found consumer products and retail services including entertainment, dining, delivery, travel, and other services. The company covers a wide range of areas, including food delivery, in-store catering, purchase of movie tickets, shared bikes, online car-hailing, purchase of train tickets, purchase of air tickets, hotel tourism, homestay apartment, and other services. Covering the whole country. During this epidemic, the company's tourism industry was most affected.

However, Meituan has used the above five strategies well to overcome this crisis.

First of all, Meituan's response is to integrate into the current market environment and adjust its sales methods in line with the trend. This is a very typical and useful strategy to deal with crisis times, especially during the epidemic. Customers can search for a series of service recommendations such as hotels and foods to be ordered on the Meituan APP. But during the epidemic, problems emerged. The government stipulates that it is not allowed to go out, disinfect if it is possible to go out, wear masks and restrict the flow of people. Almost no one eats in public restaurants. Going out to buy food has also become a problem. Even when some minor diseases appear, people cannot buy medicines in time. Meituan strengthened its original strategy at this time, which is to provide door-to-door service. The long-term delivery service ensures that Meituan will continue to serve people in the same way in an orderly manner during the epidemic. An unknown customer commented under the software, "This app is awesome, it is very difficult to go out to buy food, but the delivery staff strictly follow the regulations to bring masks, masks and gloves to deliver the food. And the food is also disinfected, not only delivered in time and safety is guaranteed.

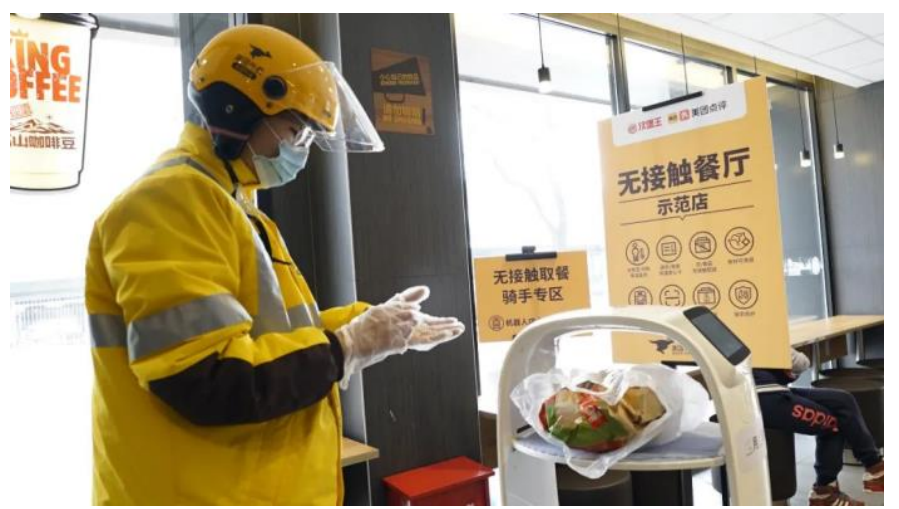

Figure 1 Meituan takeaway riders pick up food from the no-touch restaurant demonstration store [8]. 


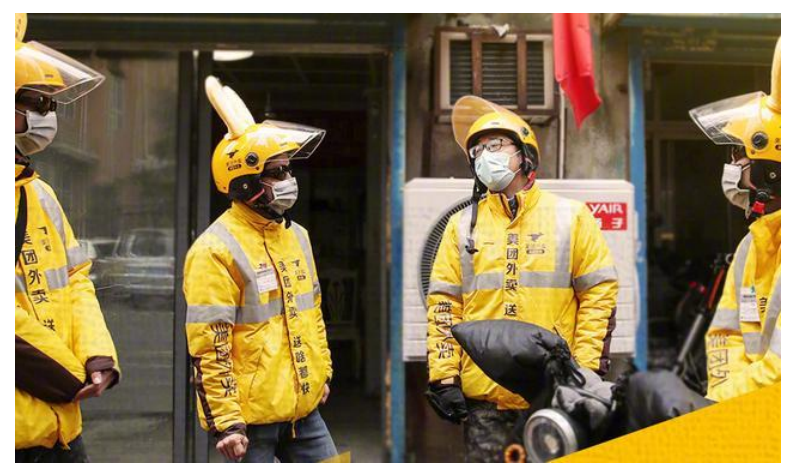

Figure2 Meituan takeaway are prepearing for their job [9].

Next, Meituan made two user-specific strategies, namely adjusting sales targets and cultivating customer loyalty. First, Meituan launched targeted services for special users, that is, people who can afford them. In the report, Meituan focused on the business development of high -star hotels. In recent years, with the rapid economic development, people's quality of life has greatly improved, and high-star hotels have become the choice of more people. Safety becomes the only concern for customers during the epidemic. Timely preferential offers, digital ordering, these advantages, promote customers to choose Meituan companies to order hotels. "Our expansion into five-star hotels has been particularly successful, where we have become an increasingly attractive online channel to help them increase their customer base and sales. It's worth noting that of the total hotel room nights spent on our platform in China, fivestar hotel room nights increased by more than $110 \%$ yearon-year in the four th quarter" [10]. Secondly, to increase customer consumption, Meituan has adopted strategies to increase customer loyalty. Meituan decided to implement a membership system and a new user welfare system to increase profitability. Members and new users are the main driving force for Meituan's continued profitability during the epidemic. Meituan seized the opportunity to allow members to increase consumption and use the benefits of new users to attract more consumers to join Meituan, so not only the original users continue to use the Meituan APP, but many new users continue to join Meituan. For example, one consumer said "I think Meituan is good. Because during the hardest time of epidemic, I thought to order food delivery online is also dangerous, so I chose to cook at home instead of ordering food delivery. I didn't use Meituan for about one month, but I already paid for the membership of that month, and what shocked me was that Meituan offered me extra one month membership on free. This approach makes $\mathrm{m}$ e very grateful. Meituan is very considerate. Sleepy Users in difficult moments. Through various methods, Meituan has gained more people's love, and they also have a $30 \%$ chance to recommend Meituan to others. This will form a virtuous circle and allow Meituan's users to grow rapidly. Meituan's efficient customer service is the main reason why it has so many loyal consumers. There are user comments "I am busy to call your customer service recently, I book the both ticket and the hotel on Meituan, but I get some problems on it. First because I cannot use pay treasure. Then I have a problem about the ticket price difference, I want to refund it, but I don't gain the money of original ticket price. At the same time, I can't live in the hotel on time because of the death of my family member. Meituan customer service has solved all these problems, and the customer service is very patient. Thank you very much." During the epidemic, people's income has declined. People began to complain about various problems against Meituan, but the excellent aftersales team of Meituan solved almost all the problems. After the problem is solved, users will be more loyal to it.

Meituan's publicity to people other than users has helped the company tide over difficulties to a large extent. Advertising is the largest, fastest, and most extensive information delivery medium. Through advertisements, Meituan delivers information on the features, functions, uses, and suppliers of the services on the APP to consumers, attracting consumers' attention and interest and promoting use. The visual and sensory reflections and inducements caused by advertisements often arouse consumers' desire to buy in reality, and at the same time expand the popularity of the product, and even arouse a certain sense of trust to increase purchases. Although advertising costs have increased during this period, more customers have been gained. About the strategy that is not shown in the financial report in Meituan, it is reasonable to say that the tactic has been adopted. First, when Meituan provides the online service of booking hotel rooms, Meituan and offline hotels are allying. As the alliance or relationship between the platform and restaurants is the foundation of carrying out service, the report does not necessarily need to emphasize this strategy. In addition, according to customers' comments about Meituan in App Store, most consumers find it convenient to book or cancel the room. These positive comments indicate that the hotel and Meituan are now forming a good relationship so that the service can have high efficiency.

Meituan has a competing company called "Are you hungry". Under the fierce competition, how does Meituan have more resources and a higher market share 
than "Are you hungry?" According to the investigation, we found that the two companies have different practices when dealing with the problems of 'overtime delivery', 'delivery in violation of regulations' and 'too many tasks assigned by the system at the same time' [10].

First of all, for the system of "exceeding the prescribed time", Meituan will fine the delivery staff $40 \%$ of the delivery fee, and "Hungry?" penalty $10 \%$ of the delivery fee. If Meituan employees overtime, almost half of the delivery fee will be gone. This kind of punishment system will allow the delivery staff to deliver items like a game to achieve high delivery efficiency. After all, no one wants to work in vain.

Regarding the problem of "the system allocates too many tasks at the same time", Meituan encourages delivery staff not to cancel orders even if they are over time. So as long as the users who have used Meituan will find that there is almost no cancellation of orders, they will be delivered as long as the delivery starts. And its competitor, "Hungry?" allows delivery staff to cancel orders. Although this is a tolerant system for delivery staff, the cancellation of orders means that customer satisfaction will decline. There is also a fine of 50 yuan for "Illegal Delivery", and a fine of only 10 yuan for "Hungry?" This greatly reduces the enthusiasm of the delivery staff.

In general, Meituan achieves high efficiency through strict, high-intensity and even inhumane management of delivery personnel. And "Hungry?" will care more about the delivery staff's feelings, so the efficiency and user satisfaction are not very high. This is why Meituan has a higher market share than "Hungry?"

\section{CONCLUSION}

In conclusion, five strategies have been summarized in this thesis. The strategies are: making relationships, keeping the price level, strengthening customer loyalty to the brand, following market trends, and maintaining companies' publicity. In the annual financial report of Meituan, these strategies have been applied to improve performance, so these methods have proven to be feasible. Meituan successfully passed this difficult time. In the market competitions, Meituan formulated strict rules to improve efficiency. This is also one of the reasons for the success of Meituan.

In the previous thesis, many enlightenments, which might help the future, can be revealed. The strategies above shows Meituan company's flexibility when facing crises, and this flexibility is not only restrained by Meituan. Any company can learn these tactics if the situations are similar.

In the unforeseeable future, enterprises would possess more confidence with the experience from triumphant cases in the past. This thesis may play a role as a mirror that reflect the past to brighten a path to the successful future.

\section{REFERENCES}

[1]State Post Bureau of the People's Republic of China. (n.d.).

http://www.spb.gov.cn/xw/dtxx_15079/202003/t20 200306 2050120.html

[2]Posts, R., \& Author zhizhi, A. (n.d.). zhizhixiaozhan.https://www.zhizhi88.com/articles/ 18979.html

[3] Irem, (2009) TECHNIQUES FOR TOUGH TIMES Don't Let the Recession Hamper Your Marketing Efforts. MARKETING SOLUTIONS, 5-6.

[4]Simkin L,Dibb S. (27th September 2011) Leadership teams rediscover market analysis in seeking competitive advantage and growth during economic uncertainty . Journal of Strategic Marketing, Vol. 20, No. 1:45-54

[5]Raggio, R. D., \& Leone, R. P. (7th may 2009). Postscript: Preserving (and Growing) Brand Value in a Downturn. Journal of Brand Managment,86: 70-91.

[6]Allen, P. (12 january 2009). Marketing tolls for survival. Chemistry\&Industry. 20-22

[7]Kay, M. (1973) Marketing During a Recession: Social Effects and Marketing Opportunities. Northeast Business \& Economics Association, 587-598

[8] Sina Finance comprehensive. (2020) How can six leading enterprises win the battle with the epidemic. http://www.aliol.com/finance/528002.html?_cf_c hl_jschl_tk_=pmd_tfHDZjf94ucmGkBXhRmDjG Uqrb76Dc0I0B7woeR22OE-1633423619-0gqNtZGzNAeWjenBszQNR

[9] 21st Century Business Review. (2020) College graduates deliver food, and the proportion of meituan highly-educated riders rose to 24.7 . https://www.163.com/dy/article/FHOH2A3S05199 $4 \mathrm{KN} . h \mathrm{tml}$

[10]Meituan. (2020, October 30). Finance, Meituan. (2020, September 30). The Board of Directors of Meituan (the "Company") (the "Board") is pleased to announce the company's unaudited consolidated business for the three months ended September 30, 2020 The Retrieved June 2, 2021, the Board of Directors of Meituan (the "Company") is pleased to announce the unreviewed consolidated results of the Company for the three months ended September 30, 2020 http://mediameituan.todayir.com/202101071144241709488301 _tc.pdf 